\title{
Precordial ST segment depression in patients with inferior myocardial infarction: clinical implications
}

\author{
J S GELMAN, A SALTUPS \\ From the Cardiology Unit, Prince Henry's Hospital, Melbourne, Australia
}

\begin{abstract}
SUMMARY A prospective assessment of precordial ST segment depression in acute inferior myocardial infarction was made comparing clinical characteristics, and the hospital and post-hospital course. One hundred and ten consecutive patients with inferior infarction and without previous infarction were allocated to three electrocardiographic groups. Group 1 consisted of 35 patients with inferior or inferolateral infarction without precordial ST depression. Group 2 consisted of 59 patients with $1 \mathrm{~mm}$ or more precordial ST depression, subdivided into 36 patients with transient ST depression (2t) and 23 patients with ST depression persisting for 48 hours or more after the admission electrocardiogram (2p). Group 3 had 16 patients with definite inferoposterior or inferoposterolateral infarction. Patients in group 2 were older than those in group 1, had higher peak creatine kinase levels, and had atrial fibrillation and atrioventricular block requiring treatment more frequently. These clinical differences were largely contributed by subgroup $2 \mathrm{p}$. Compared with group 1 , subgroup $2 \mathrm{p}$ contained relatively more women and there were more instances of ventricular fibrillation and left ventricular failure. The hospital stay was longer in this subgroup. Compared with group 3, patients in group $2 \mathrm{p}$ were older, had a greater proportion of women, and were more commonly previously hypertensive. Patients in subgroup $2 \mathrm{t}$ had higher creatine kinase levels and more frequent atrioventricular block than those in group 1. Differences in hospital mortality and in other clinical features were not significant among the groups. During a mean follow-up period of 17 (12 to 32) months left ventricular failure was more common in subgroup $2 \mathrm{p}$ compared with groups 1 and $2 \mathrm{t}$ and recurrent infarction occurred more often in subgroup $2 \mathrm{p}$ compared with group 1 . No late deaths occurred in groups 1 and 3 , but three (5\%) patients in group 2 died.
\end{abstract}

Our data show that persistent precordial ST depression in patients with inferior infarction is a reliable marker of an adverse hospital and post-hospital course.

The extent of myocardial damage and the presence of multivessel coronary artery disease are major prognostic factors in acute myocardial infarction. ${ }^{1-3}$ Precordial ST segment depression with inferior myocardial infarction may indicate ischaemia or infarction of the anteroseptal region, posterior left ventricular wall, or both. Alternatively, these changes may be "reciprocal" to ST changes in the inferior electrocardiographic leads. Hence, identification of the significance of precordial ST segment depression in inferior infarction may have important clinical implications.

Precordial ST changes in inferior infarction have been assessed in terms of myocardial involvement by nuclear scanning techniques ${ }^{4-7}$ and coronary arterio-

Accepted for publication 20 July 1982 graphic findings. ${ }^{589}$ The conflicting results reported may reflect differences in patient selection or in the electrocardiographic diagnosis and interpretation of precordial ST segment depression. In particular, the significance of persistent ST depression has not been previously examined in detail. Persistent ST depression, despite resolution of inferior ST elevation, may indicate significant ischaemia or even infarction rather than a reciprocal phenomenon.

In this study of patients with inferior infarction, the implications of precordial ST depression are evaluated by comparison of clinical characteristics, and hospital and post-hospital morbidity and mortality.

\section{Patients and methods}

The study comprised 110 consecutive patients with 
acute transmural inferior infarction, without previous infarction, admitted to Prince Henry's Hospital Coronary Care Unit, Melbourne, between April 1978 and January 1980.

A diagnosis of acute inferior transmural infarction was based on: (i) a history of prolonged chest pain suggesting myocardial ischaemia, occurring within 48 hours before admission; (ii) development of pathological $\mathrm{Q}$ waves ( $>1 \mathrm{~mm}$ deep, $\geqslant 0.04 \mathrm{~s}$ in duration) in electrocardiographic leads II, III, and aVF, and (iii) characteristic serial changes in serum levels of creatine kinase and lactic dehydrogenase.

Patients with previous myocardial infarction or left bundle-branch block were excluded.

\section{ELECTROCARDIOGRAPHIC CLASSIFICATION}

All patients showed changes of transmural infarction (development of abnormal $Q$ wave, ST segment elevation, and $\mathrm{T}$ wave inversion) in leads II, III, and aVF.

A diagnosis of inferolateral infarction was made when these abnormalities also appeared in leads V5 and V6. Associated posterior infarction was diagnosed when the electrocardiogram showed the development of prominent primary $R$ waves in leads V1 and V2 $(R / S \geqslant 1)$ with related ST depression and tall, wide, symmetrical $\mathrm{T}$ waves in leads $\mathrm{V} 1$ and $\mathrm{V} 2$.

The electrocardiograms of patients with inferior and inferolateral infarction were subclassified according to the presence or absence of significant ST segment depression ( $\geqslant 1 \mathrm{~mm}$ deep, $\geqslant 0.08 \mathrm{~s}$ ) in at least two of the chest leads V1 to V4. Thirty-five patients had inferior or inferolateral infarction without significant precordial ST depression (group 1). Fifty-nine patients had inferior or inferolateral infarction with associated precordial ST depression (group 2). The ST depression resolved within 48 hours of admission in 36 of these 59 patients-subgroup 2t ("transient" ST depression). Also included in this subgroup were those patients whose electrocardiogram showed precordial ST depression, but who died within the first 48 hours. Of the 59 patients, 23 had ST depression which persisted for at least 48 hours-subgroup 2p ("persistent" ST depression).

Group 3 comprised 16 patients with definite electrocardiographic evidence of posterior infarction.

\section{FOLLOW-UP}

The follow-up period ranged from 12 to 32 months (mean 17 months). At the time of follow-up three patients (3\%), two from group 1 and one from group 3, could not be reached by letter, telephone, or through the local medical officer or the government statistician.

STATISTICAL ANALYSIS

Data are expressed as mean \pm SEM. Assessment of the statistical significance of differences between two electrocardiographic groups was based on the unpaired $t$ test and Fisher's exact test as appropriate. A p value of $<0.05$ was considered significant.

\section{Results}

PATIENT CHARACTERISTICS (Table 1)

Patients with persistent precordial ST depression (2p) had a mean age of 62 years, which was significantly older than those in all other groups $(p<0.05)$.

Men predominated in all groups, except subgroup $2 p$ which had an almost equal sex ratio $(p<0.05)$.

Angina before infarction occurred with similar frequency in groups 1 and 2 . In group 3, eight (50\%) patients had previous angina (NS).

Of subgroup $2 p, 52 \%$ had been hypertensive before hospital admission, compared with subgroup $2 t$ $(p<0.05)$ and group $3(p<0.05)$. Comparison with group 1 did not reach statistical significance.

The time from onset of symptoms to the initial electrocardiogram was similar in patient groups.

\section{HOSPITAL COURSE (Table 2)}

The average hospital stay for subgroup $2 p$ was 14 days compared with 10 days for group $1(p<0 \cdot 05)$. Groups 2 and 3 had similar periods in hospital.

The mean peak creatine kinase level of group 2 patients was $1779 \mathrm{U} / 1$ which was significantly higher $(p<0.001)$ than that of those in group $1(1090 \mathrm{U} / 1)$. The levels in subgroups $2 t$ and $2 p$ and group 3 were comparable and were all higher $(p<0.005)$ than in group 1.

Sinus and junctional bradycardia and paroxysmal supraventricular tachycardia occurred with similar frequency in each of the groups. Only one patient (3\%) in group 1 developed atrial fibrillation compared with $10(17 \%)$ from group $2(p<0.05)$. Of these 10 patients in group 2 , seven were in subgroup $2 p$ and three were in subgroup $2 t(p<0.05)$. Two patients in group 3 had atrial fibrillation. Atrial flutter occurred in one patient (4\%) from group $2 \mathrm{p}$.

Although ventricular arrhythmias (including ventricular fibrillation) appeared to be more common in group 2 than in group 1, this difference was not statistically significant. Ventricular fibrillation, however, was significantly more common in subgroup 2 than in group $1(22 \%$ vs. $3 \%, p<0.05)$. Ventricular arrhythmias, including fibrillation, occurred with comparable frequency in groups 1 and 3.

Atrioventricular block, requiring intravenous atropine or temporary pacing, occurred in 18 patients (31\%) in group 2 but in only one $(3 \%)$ patient from group $1(p<0.001)$. Patients in subgroups $2 t$ and $2 p$ had a similar incidence of atrioventricular block ( $28 \%$ and $35 \%$, respectively). Two (13\%) group 3 
Table 1 Clinical characteristics

\begin{tabular}{|c|c|c|c|c|c|}
\hline & \multirow[t]{2}{*}{ Group I } & \multicolumn{3}{|l|}{ Group 2} & \multirow[t]{2}{*}{ Group 3} \\
\hline & & Total 2 & $2 t$ & $2 p$ & \\
\hline $\begin{array}{l}\text { Number of patients } \\
\text { Age }(y) \\
\text { Male:female } \\
\text { Past angina } \\
\text { Past hypertension } \\
\text { Time from onset of } \\
\quad \text { symptoms to initial } \\
\text { electrocardiogram }(h)\end{array}$ & $\begin{array}{l}35 \\
54 \pm 2 \\
5: 1 \\
8(23 \%) \\
10(29 \%)\end{array}$ & $\begin{array}{l}59 \\
59 \pm 1^{\star} \\
2: 1 \\
15(25 \%) \\
21(36 \%)\end{array}$ & $\begin{array}{l}36 \\
56 \pm 2 \\
4: 1 \\
8(22 \%) \\
9(25 \%)\end{array}$ & $\begin{array}{l}23 \\
62 \pm 2 \ddagger \\
1: 1 \dagger \\
7(30 \%) \\
12(52 \%)\end{array}$ & $\begin{array}{l}16 \\
54 \pm 3 \\
7: 1 \\
8(50 \%) \\
3(19 \%)\end{array}$ \\
\hline
\end{tabular}

${ }^{\star} \mathrm{p}<0.05$.

$+p<0.01$.

$\neq \mathrm{p}<0.005$.

$p$ value in Tables $1-3$ refers to the difference between group 1 and group indicated.

Table 2 Hospital course

\begin{tabular}{|c|c|c|c|c|c|}
\hline & \multirow[t]{2}{*}{ Group I } & \multicolumn{3}{|l|}{ Group 2} & \multirow[t]{2}{*}{ Group 3} \\
\hline & & Total 2 & $2 t$ & $2 p$ & \\
\hline $\begin{array}{l}\text { Hospital stay (d) } \\
\text { Peak creatine kinase } \\
\text { (normal <220 U/l) } \\
\text { Atrial fibrillation }\end{array}$ & $\begin{array}{l}10 \pm 1 \\
1090 \\
\pm 112 \\
1(3 \%)\end{array}$ & $\begin{array}{l}13 \pm 1 \\
1779 \ddagger \\
\pm 112 \\
10(17 \%)^{\star}\end{array}$ & $\begin{array}{l}12 \pm 1 \\
1798 \ddagger \\
\pm 149 \\
3(8 \%)\end{array}$ & $\begin{array}{l}14 \pm 2^{\star} \\
1774 \ddagger \\
\pm 161 \\
7(30 \%) \ddagger\end{array}$ & $\begin{array}{l}12 \pm 1 \\
1794 \ddagger \\
\pm 238 \\
2(13 \%)\end{array}$ \\
\hline $\begin{array}{l}\text { Ventricular arrhythmias } \\
\text { needing treatment } \\
\text { Ventricular fibrillation }\end{array}$ & $\begin{array}{l}19(54 \%) \\
1(3 \%)\end{array}$ & $\begin{array}{l}40(68 \%) \\
9(15 \%)\end{array}$ & $\begin{array}{l}26(72 \%) \\
4(11 \%)\end{array}$ & $\begin{array}{l}14(61 \%) \\
5(22 \%)^{\star}\end{array}$ & $\begin{array}{l}8(50 \%) \\
1(6 \%)\end{array}$ \\
\hline $\begin{array}{l}\text { Atrioventricular block } \\
\text { needing treatment } \\
\text { Left ventricular failure }\end{array}$ & $1(3 \%)$ & $18(31 \%)^{\star \star}$ & $10(28 \%) \ddagger$ & $8(35 \%) \ddagger$ & $2(13 \%)$ \\
\hline $\begin{array}{l}\text { Mild } \\
\text { Moderate } \\
\text { Severe } \\
\text { Total } \\
\text { Further infarction } \\
\text { Death }\end{array}$ & $\begin{array}{l}8 \\
1 \\
1 \\
10(29 \%) \\
2(6 \%) \\
1(3 \%)\end{array}$ & $\begin{array}{l}19 \\
6 \\
2 \\
27(46 \%) \\
\overline{5}(8 \%)\end{array}$ & $\begin{array}{l}8 \\
1 \\
2 \\
11(31 \%) \\
\frac{2}{2(6 \%)}\end{array}$ & $\begin{array}{l}11^{\star} \\
\frac{5^{\star}}{16}(70 \%) \ddagger \\
\frac{-}{3(13 \%)}\end{array}$ & $\begin{array}{l}3 \\
3 \\
1 \\
7(44 \%) \\
\overline{2}(13 \%)\end{array}$ \\
\hline
\end{tabular}

${ }^{\star} \mathrm{p}<0.005$.

$\neq p<0.005$.

${ }_{\star \star} \mathrm{p}<0.001$

Table 3 Follow-up data

\begin{tabular}{|c|c|c|c|c|c|}
\hline & \multirow[t]{2}{*}{ Group I } & \multicolumn{3}{|l|}{ Group 2} & \multirow[t]{2}{*}{ Group 3} \\
\hline & & Total 2 & $2 t$ & $2 p$ & \\
\hline $\begin{array}{l}\text { Hospital survivors } \\
\text { Angina pectoris } \\
\text { Coronary graft surgery }\end{array}$ & $\begin{array}{l}34 \\
12(35 \%)\end{array}$ & $\begin{array}{l}54 \\
19(35 \%)\end{array}$ & $\begin{array}{l}34 \\
16(48 \%)\end{array}$ & $\begin{array}{l}20 \\
3(15 \%)\end{array}$ & $\begin{array}{l}14 \\
4(29 \%)\end{array}$ \\
\hline for severe angina & 2 & 2 & 1 & 1 & 1 \\
\hline $\begin{array}{l}\text { Supraventricular arrhythmias } \\
\text { Ventricular arrhythmias }\end{array}$ & - & 4 & 3 & 1 & - \\
\hline $\begin{array}{l}\text { needing treatment } \\
\text { Left ventricular failure } \\
\text { Recurrent infarction }\end{array}$ & $\begin{array}{l}1 \\
2(6 \%)\end{array}$ & $\begin{array}{l}3 \\
14(26 \%)^{\star}\end{array}$ & $\begin{array}{l}2 \\
5(15 \%)\end{array}$ & $\begin{array}{l}1 \\
9(45 \%) \ddagger\end{array}$ & $\overline{3(21 \%)}$ \\
\hline Anterior & - & 4 & 2 & 2 & - \\
\hline Lateral & 1 & 2 & 1 & 1 & - \\
\hline Uncertain site & - & 2 & 1 & 1 & - \\
\hline Total & $1(3 \%)$ & $8(15 \%)$ & $4(12 \%)$ & $4(20 \%)^{\star}$ & - \\
\hline Death & - & $3(6 \%)$ & $1(3 \%)$ & $2(10 \%)$ & - \\
\hline
\end{tabular}

${ }^{\star} \mathrm{p}<0.05$.

$\neq p<0.005$. 
patients had atrioventricular block needing treatment (NS).

Left ventricular failure was graded as mild, moderate, or severe.

Mild left ventricular failure was diagnosed in the presence of basal pulmonary crepitations not cleared with coughing, a third heart sound, and radiological pulmonary venous congestion. Moderate left ventricular failure was defined by the presence of the above signs, radiological interstitial or alveolar oedema, and a normal blood pressure. A diagnosis of severe left ventricular failure was made when the features just described were accompanied by arterial hypotension requiring inotropic support.

Cardiac failure developed in $10(29 \%)$ group 1 and 27 (46\%) group 2 patients (NS). Of the latter 27 patients, $16(59 \%)$ were in subgroup $2 \mathrm{p}$. The occurrence of left ventricular failure in $70 \%$ of this subgroup was more than twice that in group $1(\mathrm{p}<0.005)$ and in subgroup $2 t(p<0.005)$. Seven patients $(44 \%)$ in group 3 had left ventricular failure (NS).

\section{Hospital deaths}

One (3\%) group 1 patient, a 69 year old woman with inferolateral infarction who developed cardiogenic shock, died within 24 hours of admission.

Five (8\%) group 2 patients died who were older than 60 years, and three of whom were women. Two had cardiogenic shock, one had left ventricular rupture, one had severe mitral regurgitation and ventricular arrhythmias with cardiac failure, and one had intractable ventricular fibrillation.

Both (13\%) group 3 patients who died were older than 70 years and were men. One developed cardiogenic shock and the other bronchopneumonia, on a background of ventricular arrhythmias, mitral regurgitation, and probable right ventricular infarction.

\section{FOLLOW-UP DATA (Table 3)}

Angina pectoris after discharge from hospital occurred with similar frequency in groups 1,2 , and 3 . Of patients from subgroup $2 t, 48 \%$ developed angina compared with $17 \%$ from subgroup $2 p(p<0.05)$. Of the 31 group 1 and 2 patients who developed angina, 12 (39\%) had angina before the infarction. All four group 3 patients with post-infarction angina had pre-existent angina.

\section{Coronary anatomy}

Disabling angina was investigated by coronary arteriography in seven patients (two from group 1, four from group 2, and one from group 3). All seven had significant narrowing $(\geqslant 75 \%$ luminal diameter reduction) in a dominant right coronary artery. Disease was confined to this artery in two patients (both subgroup $2 t$ ) and operation was not recommended. Two patients (one from group 1, the other from group 3) had additional disease in the left anterior descending and left circumflex arteries, respectively. Triple vessel disease was found in the remaining three patients (one from group 1 and two from subgroup $2 p$ ). These five patients (two with double and three with triple vessel disease) were considered suitable for surgery and underwent aortocoronary bypass three to 31 months (mean 20 months) after the inferior infarction.

Three patients who died during the initial hospital admission had triple vessel disease, demonstrated at necropsy in two cases and by coronary arteriography performed because of severe acute mitral regurgitation and cardiac failure in the remaining one.

No correlation was found between the pattern of coronary disease and electrocardiographic criteria in this small select group.

Arrhythmias occurring after leaving hospital and which required treatment were documented in one (3\%) group 1 patient and seven (44\%) group 3 patients (NS).

\section{Follow-up electrocardiograms}

Features of previous inferior infarction were present in all electrocardiograms, except two which had returned to normal. There was electrocardiographic evidence of further infarction in seven patients. Among subgroup $2 p$ patients, precordial ST depression had resolved in all but one patient.

As frequent electrocardiograms were not recorded routinely during the follow-up period, the exact time of resolution of the ST segment depression is not known.

Cardiac failure developed in two patients $(6 \%)$ from group 1 and $14(26 \%)$ patients from group $2(\mathrm{p}<0.05)$. Groups 2 and 3 had a similar incidence of cardiac failure. Nine (39\%) patients in subgroup $2 p$ were found to have cardiac failure. This incidence was significantly higher $(p=0.02)$ than that for groups 1 and $2 t$. Comparison with the incidence of $23 \%$ in group 3 patients was not significantly different.

Myocardial infarction occurred in one (3\%) group 1 patient and eight (14\%) group 2 patients (NS). Of the eight group 2 patients, four were from subgroup $2 \mathrm{p}$. Recurrent infarction developed in $20 \%$ of subgroup $2 p$ compared with $3 \%$ of group 1 ( $p<0.05)$.

There were no deaths at the time of follow-up among the $32(94 \%)$ group 1 hospital survivors. Two patients were lost to follow-up. There were three deaths (6\%) among group 2 hospital survivors. Two were associated with further myocardial infarction and one with respiratory failure caused by emphysema. All group 3 hospital survivors were alive at follow-up. One patient could not be traced. 


\section{Discussion}

The modern trends in management of acute myocardial infarction include early identification of patients at high risk of subsequent coronary events. A more aggressive therapeutic approach aiming to preserve myocardial function and improve long term prognosis may be offered to such patients. This approach, however, poses serious logistic problems in many busy cardiology departments. Our findings suggest that patients at high risk after acute inferior infarction can be identified by simple electrocardiographic criteria.

Precordial ST segment depression in our patients with inferior infarction was associated with older age, higher creatine kinase levels, more frequent atrial fibrillation, significant atrioventricular block, and post-hospital cardiac failure. Other studies have shown higher creatine kinase levels and depressed ejection fraction in patients with acute inferior infarction and precordial ST depression. ${ }^{45} 7$ Croft and colleagues ${ }^{6}$ did not evaluate clinical variables, but found no difference in ejection fraction. We have been unable to find any previous publications on long term clinical evaluation of these electrocardiographic changes.

The time delay between onset of symptoms and the admission electrocardiogram was similar for groups 1 and 2. Therefore, precordial ST depression and its clinical implications could not be explained by differences in the times of electrocardiographic recording.

Analysis of the persistence of precordial ST depression has clearly defined an important clinical subset. Those patients in whom precordial ST depression was present for at least 48 hours after admission to hospital contributed much of the morbidity and mortality of group 2 .

Infarct size, as assessed by peak creatine kinase levels, was similar in subgroups $2 t$ and $2 p$. Left ventricular failure (acute and chronic) and atrial fibrillation, however, were more common in the latter subgroup. There are two possible explanations. First, patients with persistent precordial ST depression had a significantly higher incidence of past hypertension which may have led to some degree of impairment of underlying myocardial performance. Myocardial infarction in this setting may result in a greater tendency to left ventricular failure and atrial fibrillation. Secondly, persistent precordial ST depression may represent significant myocardial ischaemia either adjoining or remote from the region of inferior infarction. This could contribute to ventricular dysfunction and atrial fibrillation without necessarily affecting creatine kinase release.

Although persistent ST depression was associated with an adverse clinical course, even transient precordial ST depression correlated with higher peak creatine kinase levels and more frequent occurrence of atrioventricular block requiring treatment. Therefore, transient ST depression should not be dismissed as merely a "reciprocal" event.

There was a low occurrence of post-infarction angina in subgroup $2 \mathrm{p}$ compared with subgroup $2 \mathrm{t}$. This observation is difficult to explain. The significantly higher incidence of symptomatic left ventricular failure in subgroup $2 p$, however, may have resulted in reduced exercise capacity manifest as dyspnoea rather than chest pain.

Although the groups were small, the patient numbers were sufficient to show statistically significant differences between groups 1 and 2 . A larger number of patients in group 3 may have disclosed other significant differences among the groups.

Exercise stress testing, nuclear scanning, and coronary arteriography were not routinely performed since the study was designed to assess the clinical rather than the anatomical significance of precordial ST depression. It is of interest, however, that anterior transmural infarction developed in four (7\%) group 2 patients but in none from groups 1 or 3 . Furthermore, though comparison of subgroup $2 p$ and group 3 ("true" posterior infarction) did show similar creatine kinase levels, there were major differences in patient characteristics.

Whatever the anatomical correlations of precordial ST segment depression in inferior infarction, the study has clearly shown a reliable marker of an adverse hospital and late clinical course.

\section{References}

1 Norris RM, Caughey DE, Deeming LW, Mercer CJ, Scott PJ. Coronary prognostic index for predicting survival after recovery from acute myocardial infarction. Lancet 1970; ii: 485-8.

2 Oberman A, Jones WB, Riley CP, Reeves TJ, Sheffield LT, Turner ME. Natural history of coronary artery disease. Bull NY Acad Med 1972; 48: 1109-25.

3 Taylor CJ, Humphries JO, Mellits ED, et al. Predictors of clinical course, coronary anatomy and left ventricular function after recovery from acute myocardial infarction. Circulation 1980; 62: 960-70.

4 Shah PK, Pichler M, Berman DS, et al. Noninvasive identification of a high risk subset of patients with acute inferior myocardial infarction. Am $\mathcal{F}$ Cardiol 1980; 46: 91521.

5 Gibson RS, Crampton RS, Holt N, Carabello BA, Beller GA. Precordial ST depression in patients with acute inferior myocardial infarction: clinical, scintigraphic and angiographic correlations (abstract). Circulation 1981; 64, suppl IV: 85 .

6 Croft CH, Woodward W, Nicod P, et al. Significance of "reciprocal" anterior ST segment depression in acute 
inferior myocardial infarction (abstract). Circulation 1981; 64, suppl IV: 85.

7 Goldberg HL, Borer JS, Jacobstein JG, Kluger J, Scheidt SS, Alonso DR. Anterior S-T segment depression in acute inferior myocardial infarction: indicator of posterolateral infarction. Am f Cardiol 1981; 48: 1009-15.

8 Chaitman BR, Waters DD, Corbara F, Bourassa MG. Prediction of multivessel disease after inferior myocardial infarction. Circulation 1978; 57: 1085-90.

9 Salcedo JR, Baird MG, Chambers RJ, Beanlands DS.
Significance of reciprocal S-T segment depression in anterior precordial leads in acute inferior myocardial infarction: concomitant left anterior descending coronary artery disease? Am $\mathcal{F}$ Cardiol 1981; 48: 1003-8.

Requests for reprints to Dr A Saltups, Cardiology Unit, Prince Henry's Hospital, Melbourne 3004, Victoria, Australia. 